\title{
Effectiveness of Graphic Training Technologies in Today's Environment
}

\author{
Elena Oparina ${ }^{1}$ and Irina Stolbova ${ }^{1}$ \\ ${ }^{1}$ Perm National Research Polytechnic University, Komsomolsky pr. 29, Perm, 314990, Russia
}

\begin{abstract}
Today the higher education system should guarantee a confident transition to the digital era, provide training for professionals in demand in the labor market, who have digital literacy and thoroughly know the Internet technologies. In this paper, the authors investigate the problem of subject learning management and digital transformation of the educational process on the example of basic geometric-graphic training of junior students in a technical university. The experience of implementation of the GGT distance course on the Moodle platform and the system of automated control of educational results, as well as their use in various forms of education: full-time, distance and mixed, is described. Positive and negative aspects of distance learning are discussed. The paper presents the results of a survey of students, as well the study of the quality of knowledge gained in the discipline in various forms of education based on automated control of current educational tests. The study analyzes the learning outcomes shown by the students of the Mining Faculty of PNRPU over the past several years with various forms of organizing the course of GGT. The effectiveness of using relevant educational technologies in the framework of geometric and graphic training at PNRPU is assessed. The data of the survey of students, showing their attitude to distance learning, are given. It is concluded that in order to achieve the best results in teaching, a mixed approach is optimal, combining the use of distance learning with traditional classroom studies of students under the guidance of a teacher.
\end{abstract}

\section{Keywords}

Digitalization, distance learning, mixed learning, geometric and graphic training.

\section{Introduction}

Globalization and computerization are the main features of the modern society. Rapidly disseminated and multiplying information becomes the main resource for development and significantly affects all sectors and spheres of life: science, technology, social environment, culture and education. The comprehensive process of informatization of the modern world creates the potential for innovative development of the economy and society, which ensures transition to a new level - the global digitalization era.

Education as one of the most important spheres of human activity ensures formation of the intellectual potential of society. Initially, informatization of education was understood as " widespread introduction of electronic computers in the educational process," and then inevitably turned into systematically organized work at broad transformation of the learning process [1]. Today, the most obvious way of the educational process informatization is the active use of Internet technologies. The Internet has substantially filled the life of a modern person and become an integral part of both professional and educational activities of a person. In today's rapidly changing world, when the principle of "education for life" is replaced by "education throughout life" or "continuing education," distance or on-line learning is recognized by experts as the most convenient form of education [2]. Today, the university educational system must guarantee confident transition to the digital era, provide

GraphiCon 2021: 31st International Conference on Computer Graphics and Vision, September 27-30, 2021, Nizhny Novgorod, Russia EMAIL: olga170800@mail.ru (E.A. Oparina); stolbova.irina@gmail.com (I. D. Stolbova)

ORCID: 0000-0001-5943-3837 (E.A. Oparina); 0000-0002-0546-9428 (I. D. Stolbova)

(c) (i) 2021 Copyright for this paper by its authors.

Use permitted under Creative Commons License Attribution 4.0 International (CC BY 4.0).

CEUR Workshop Proceedings (CEUR-WS.org) 
training for specialists in demand in the labor market, possessing digital literacy, and easily and fluently practicing Internet technologies [3].

The coronavirus pandemic has with renewed vigor clashed opponents and supporters of digital education not only in Russia, but around the world. The teaching community is actively discussing positive and negative aspects of these forms of education. As positive aspects are noted: flexibility, modularity, parallelism, coverage of a large audience, efficiency, manufacturability, individuality, social equality, internationality, less emotional and psychological tension, ability to participate in the educational process being at a great distance. The following is put forward as negative sides: lack of proper motivation, dubious quality of massive open online courses, lack of material and technical support, actual anonymity of materials sent by students for verification, weak authorship verification procedure, lack of direct communication between teachers and students, complexity of the methodological plan (necessity to develop a large number of electronic teaching materials, presentations, tests, assignments, etc.) The problems of the deteriorating quality of higher education and the increasing load on teachers during the transition to distance learning are also discussed. One of the risks inherent in online learning is its growing formalization, both in the organization of training and in its process. This can seriously affect students' learning, health, cognitive ability, behavior and quality of learning outcomes. Formalization of education can also have serious consequences for social development [4].

As practice shows, the university electronic educational environment includes issues of general management of an educational institution, the development of various subject-based courses and their implementation through adequate digital technologies and teaching methods [5]. Conceptually, the digitalization of subject areas implies optimization, adaptation and digital transformation of the content of academic disciplines within the framework of the Federal State Educational Standard of Higher Education, as well as development of the communicative competencies of educational activity subjects.

Currently, some experience has already been accumulated in the development of digitalization systems in universities, to a greater extent concerning general issues of the activities of educational institutions [6]. Also presented are studies of the educational process organization, combining traditional teaching methods with e-learning and distance learning technologies, making it more flexible and convenient for both students and teachers [7,8]. At the same time, digitalization is not yet integrated with systems that provide management of the process of subject learning and, which is most important, constant monitoring of learning outcomes [9].

Many universities are actively engaged in "digitization" of their educational resources and see the main result of the updated technology in improving the quality of training. However, effectiveness of the use of new learning technologies is determined not only by high-quality "digitization" of educational materials, but also by creation of a developed system of network services ensuring availability of educational resources, as well as allowing to organize continuous monitoring of students' progress.

Currently, mixed learning is being widely studied, when distance learning resources are used within the framework of traditional classical education, which can be used by students independently at any place and at a convenient time. Combinations of traditional education and communication educational innovations are at the level of experimenting. For example, for successful training at the design stage of technical objects (development of algorithms, execution of design documentation), the ratio of traditional training and distance learning is fixed as $30 \%$ to $70 \%$, respectively [10]. However, the question of this ratio changing in the course of mastering the professional training program, about different forms of educational activity corresponding to it (lectures, practical classes, laboratory practice, students' independent work) remains open.

In this regard, the experience of organizing a digital educational environment (DEE) in the management of specific subject learning and assessing effectiveness of the technologies used by means of end-to-end control of educational results is of interest. As an example of subject teaching, the study examines the geometric-graphic training of students of the Mining Faculty of the Perm National Research Polytechnic University (PNRPU). 


\section{Actual technologies within the framework of the GGT at PNRPU}

One of the types of subject training is basic geometric-graphic training (GGT) of students of a technical university, the purpose of which is to form readiness of future graduates for design and engineering activities [11]. For many years, within the framework of the GGT for students of PNRPU, much attention has been paid to the processes of informatization and digitalization [8,12-14]. Graphic disciplines (descriptive geometry, engineering graphics, computer graphics) in a technical university are the first professionally oriented disciplines that students are taught already in their junior years. Success in mastering these subjects serves as an indicator of the professional competence of the future engineer, who, along with the graphic language, is fluent in modern software for graphic modeling. In lectures, practical and laboratory classes, a wide range of modern CAD capabilities are used, which provide an innovative quality of teaching methods, as well as a higher level of students' preparation for modern design and engineering activities.

In order to ensure quality of education, a system of automated control of educational results has been developed, which constantly monitors students' learning during the educational process [15]. Currently, the SAC of the department is used in all types of control provided for in the graphic training of students, both full-time and part-time: input, current, midterm and final in the discipline.

In recent years, much attention has been paid to distance learning technologies. Training of students at our department is organized both in full-time (classroom) format and on-line - using a distance course hosted on an intra-university platform. The course is divided into modules corresponding to the modules of the curriculum. Each module consists of several topics. Each topic contains theoretical material presented in a different format, practical tasks, a laboratory workshop for mastering graphic programs, tasks in computer graphics, as well as tests to check the material studied.

During the period of self-isolation due to coronavirus infection, students and teachers in the course of distance learning used all available technical and organizational capabilities (e-mail, Skype, social networks, special intra-university educational platforms Moodle, BigBlueButton and programs, including Zoom, electronic testing, telephone, iPhone, laptop, stationary computer).

Taking into account the ambiguity of opinions about effectiveness of distance learning, our own research was carried out on the example of students of the Mining Faculty of PNRPU. The survey involved 81 people, among them, before the start of the pandemic, only $7 \%$ of the total number of respondents were constantly engaged in distance learning. During the study, the following data were obtained:

- $\quad 67 \%$ of respondents are satisfied with organization of distance learning in the discipline;

- $32 \%$ liked to study remotely more than usual classes in classrooms (35\% found it difficult to answer);

- $52 \%$ noted the good quality of the educational material, the logical sequence of the educational material and the conduct of the lessons was noted by $57 \%$;

- $61 \%$ of students noted good technical equipment and quality of software and hardware functionality;

- In the process of distance learning, there were practically no difficulties for $41 \%$;

- Only $30 \%$ of students believe that within the framework of the distance course they have the opportunity to maximize their cognitive interests;

- Only $23 \%$ of respondents enjoyed the distance learning process and 27\% acquired, from their point of view, good knowledge;

- When studying the course, $19 \%$ of students required additional assistance in addition to teaching.

The above data show that in questions concerning the opinions of students about distance learning, a positive or neutral attitude of the respondents prevails. There are no completely negative assessments. 


\section{Quality assessment of the applied technologies}

Additionally, a study was conducted of the comparative quality of the knowledge gained in the discipline in various forms of education: full-time, part-time and distance learning. For comparison, groups of students in the same direction were selected.

Fig. 1 shows test results that complete the study of specific training modules of the course. The test score is given as a percentage of the maximum possible result. The results were averaged over the studied groups of students. From these graphs, we see that the results of students who studied only remotely (correspondence department) at the beginning of their studies are significantly lower than those of full-time students (34\%). Gradually, in the learning process, the difference in results becomes less significant and as a result amounts to $11 \%$. Based on these data, we can conclude that the proposed distance learning course is quite effective.

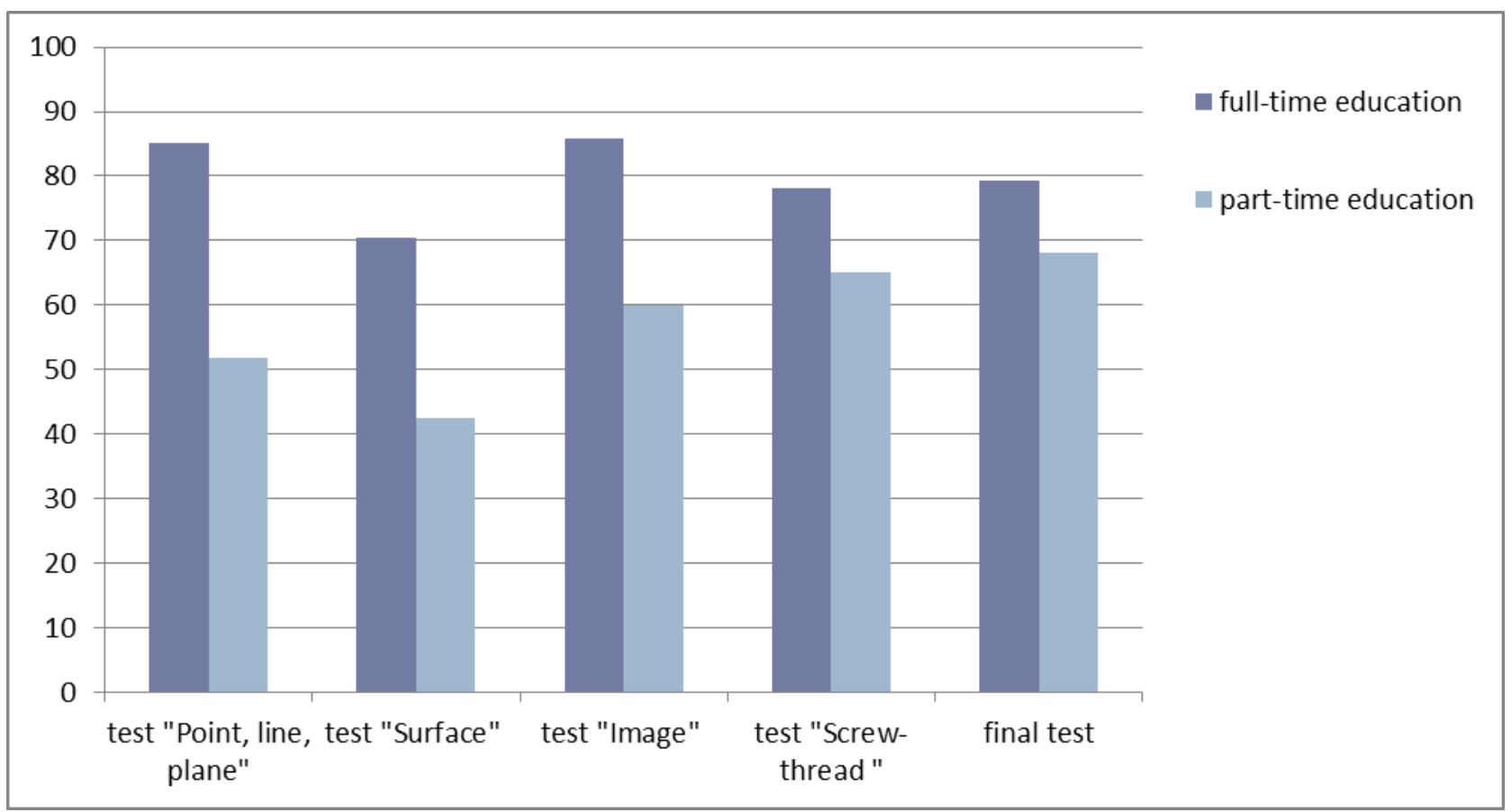

Figure 1: Comparative data on the course of geometric-graphic training by full-time and part-time students.

We also analyzed the learning outcomes that the students of the Mining Faculty have shown over the past several years with various forms of organizing the course of GGT (see Table 1 and Fig. 2, the year of entering the university is indicated). For the analysis, we used the indicators (in percent) of the level of learning and the level of mastery of subject learning. The level of learning is assessed by the average passing score in the group upon admission to the university. The level of mastering the course is assessed on average for the study group on the basis of the results of planned control activities of the educational process of GGT.

Fig. 2 shows that in 2016, with classroom teaching of students and unorganized independent work, performance indicators are correlated with each other. In 2017, the development and testing of the distance course began, which accompanied independent work of students; at the same time, an increase in the efficiency of the learning process is visible. In 2018, training was conducted in a mixed format: classroom and active use of distance, and, as can be seen from the diagram, this result showed the highest efficiency in organizing the learning process. In 2019, due to the pandemic, all educational institutions had to abruptly switch to a completely distance learning format. It was difficult for all participants in the educational process to adjust, which could not but affect the results. Shortcomings of the distance course were identified, such as lack of some teaching materials, the absence of which was compensated by full-time training. Therefore, a lot of methodological work was carried out to 
change, correct and supplement the distance course, which had a positive impact on the learning outcomes in 2020, despite a lower level of learnability of the students.

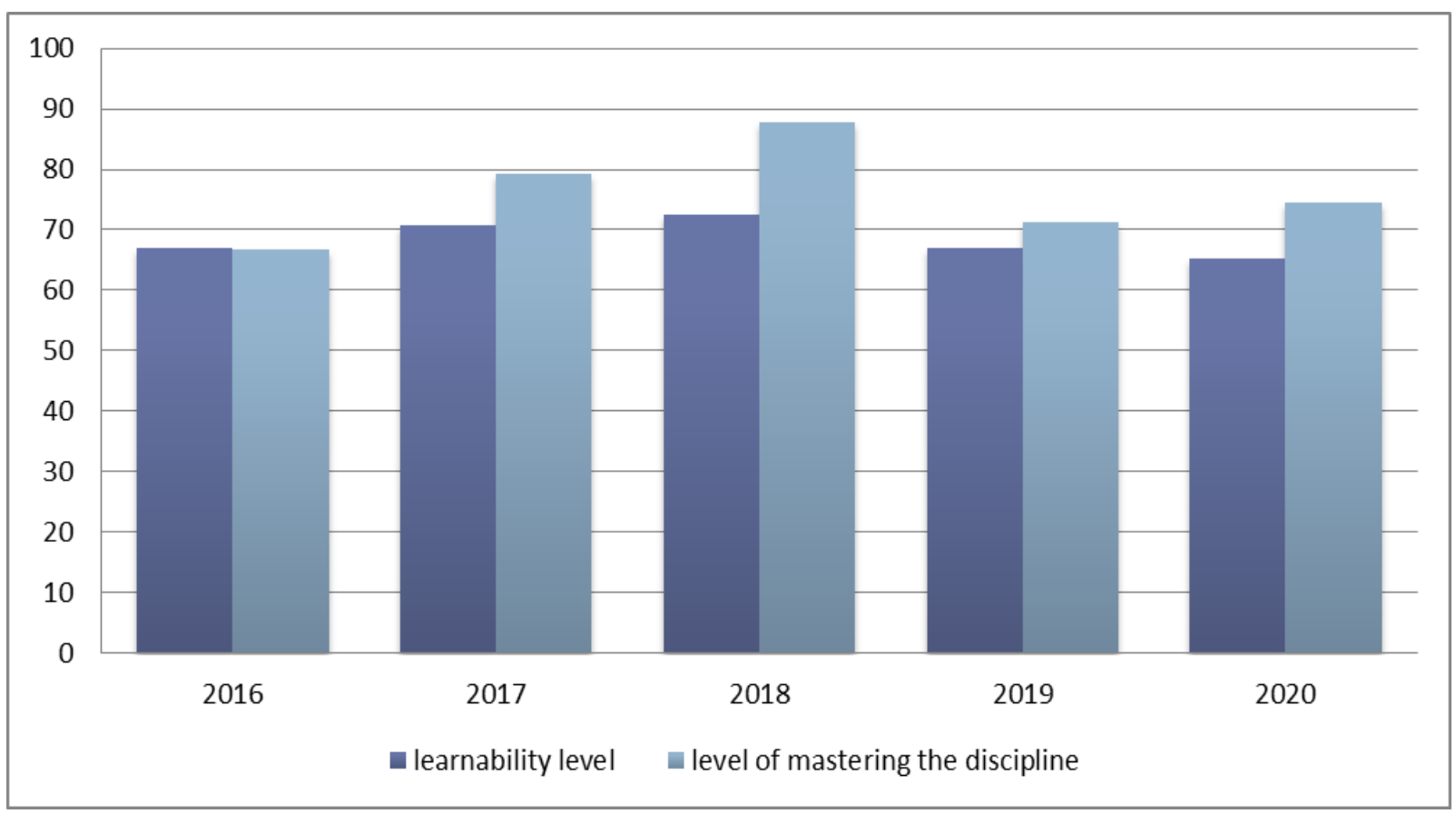

Figure 2: Effectiveness of learning during the course of geometric-graphic training.

Table 1

Effectiveness of learning during the course of geometric - graphic training depending on the form of study

\begin{tabular}{|c|c|c|c|}
\hline $\begin{array}{c}\text { Enrolment } \\
\text { year }\end{array}$ & $\begin{array}{l}\text { Learnability } \\
\text { level }\end{array}$ & $\begin{array}{l}\text { Level of } \\
\text { mastering the } \\
\text { discipline }\end{array}$ & GGT course form \\
\hline 2016 & & & Full-time (classroom) training and independent \\
\hline \multirow{3}{*}{2017} & $67,05 \%$ & $66,67 \%$ & work \\
\hline & & & Full-time training, approbation of the distance \\
\hline & $70,73 \%$ & $79,33 \%$ & course \\
\hline 2018 & $72,55 \%$ & $87,72 \%$ & Mixed learning \\
\hline \multirow[t]{2}{*}{2019} & & & Distance learning during self-isolation for \\
\hline & $67,11 \%$ & $71,35 \%$ & coronavirus infection \\
\hline \multirow[t]{2}{*}{2020} & & & Mixed learning, mainly distance learning with \\
\hline & $65,27 \%$ & $74,6 \%$ & additional course correction. \\
\hline
\end{tabular}

The data obtained can be compared with an experiment carried out by specialists from the Higher School of Economics together with their American colleagues from the University of California, Berkeley, which was carried out in the 2017-2018 academic years. Within the framework of the project, two compulsory semester courses "Engineering Mechanics" and "Technology of Building Materials" were selected in three higher educational institutions of Russia. The study participants were randomly divided into three groups: the first one was trained in a traditional format, the second watched lectures on-line and attended face-to-face seminars, the third group mastered the entire course on-line, communicating with teachers only on the forum [16].

The content of the course (learning outcomes, course topics, required literature and assignments) was the same for all students. All students had previously passed a knowledge test, as well as psychological tests. The tests helped to ensure that the composition of the three groups did not differ 
significantly in terms of USE scores, previous experience of taking online courses, as well as gender and age.

Upon completion of the courses, 294 participants (90\%) passed the final exam, which was developed by the online course teachers and independently assessed for compliance with the FSES learning outcomes. The results showed that the format of training does not affect the level of mastering the discipline, and there is also no difference in the subjective assessment of students' knowledge of the course, depending on the method of mastering the material [16].

The described experiment does not contradict our results obtained in the framework of GGT, however, there are some remarks. In our case, the study was not carried out in different time conditions and was accompanied by improvement of the distance course. In addition, it is possible to note the peculiarity of our discipline, in comparison with the example given above: GGT is distinguished by a large amount of graphic material, and students, to varying degrees, have a spatial imagination, which is largely determined by their nature. At the moment, when students perform independent tasks, it is more difficult to "digest" and control graphical information remotely. Therefore, from our point of view, the most effective form of mixed learning is when a well-developed distance learning course is accompanied by a personal contact between the teacher and the student.

This opinion is also confirmed by the final survey, which was aimed at finding out the choice of the way of education / teaching in universities by the respondents in the future. Despite the fact that the majority of respondents are generally positive about digital education, they still vote for traditional education or mixed learning (54\% and $81 \%$, respectively). Today, students still do not consider distance learning to be so stable, habitual, as to switch over to it completely. As arguments "for" full-time education, they indicate that the traditional way of teaching is much more "humane", more acceptable from the point of view of maintaining health, more effective for thorough mastering of academic disciplines, that it is difficult to study a graphic discipline remotely $[17,18]$.

\section{Conclusion}

Despite, in general, the positive results of introduction of the GGT distance course, further efforts on innovative education should be aimed not only at introduction of new technologies, but also at the development of new effective pedagogical approaches that ensure successful integration of technologies into the educational process, as well as help to overcome negative aspects of distance learning.

While it is obvious that student learnability and effectiveness of online learning, distance courses are very important, measuring these parameters is rather a difficult task. Research has shown that students lose up to $40 \%$ of their time to "frustrating experiences" with courses. The training strategy used, the lack of quick feedback, the format and quality of the training material that was developed, etc. can be considered as the reasons for inefficiency. There are several problems associated with measuring efficiency:

- There is a large number of parameters affecting effectiveness of the course, and they are not always measurable;

- $\quad$ Significance of each parameter changes depending on the type of training;

- Feedback can be both objective (easy to implement) and subjective (often difficult to capture).

If we consider various components of the course and how students perceive them and interact with it, then a number of parameters can be distinguished that can be used to influence learning efficiency:

1. Design of the course interface. No student will learn boring content. Using statistics, data, and charts is a great way to grab the student's attention from the start and build interest. Such content is visually appealing, quick to digest, and easier to remember. Good graphics can make learners instantly feel like value of the course.

2. Course information, user instructions and obvious navigation. The speed and convenience of the course depends on them.

3. Structuring the content depending on compliance with the required level of knowledge. Most people don't appreciate boring work, including reading repetitive content. It is necessary (if possible) to present only the most important and concentrated information.

4. Learning tasks need to be accompanied by interaction and learning. So, when mastering the required information, the emphasis should not be on its simple memorization, it is more important 
to help students develop the sense of mastery of the material, using, for example, open-ended questions so that students think about the content on their own. For maximum interaction in consolidating the most important provisions of the discipline, it is effective to use mixed learning, when assignments are performed independently and are sent online for verification, and key problems, common mistakes, original solutions and findings are discussed in classroom sessions or face-to-face consultations.

5. Ease of use. An online course or distance course designed and intended to be widely used should work on any device so that students can interact with content on the go. Mobile learning can also use push notifications to remind learners at different times of the day to interact with the content. Sometimes a light nudge is all a student needs to log in and take another lesson or short test, which is often what he needs to stay engaged.

6. High-quality and prompt feedback. You cannot rely solely on the final exam at the end of the course. It is necessary to conduct periodic knowledge tests after each key section and offer small tests to check assimilation in the course of mastering a certain topic.

Implementing these and other activities to improve the online course can increase student satisfaction with learning and solve some of the current problems that exist in the distance education system today.

The listed parameters make it possible to continue improving the GGT on-line process and just as successfully build work with distance learning in the future. Today, according to statistical data [19], the site of our department is one of the three best subdomains of the PNRPU portal with a daily number of visitors - 304 and page views - 578. In the do3.pstu.ru distance education system, GGT on-line courses presented by the discipline "Engineering geometry and Computer Graphics "in various areas of training, are the most attended by students and show the first result among all distance courses of subject education at the university.

\section{References}

[1] S.D. Karakozov, A.U. Uvarov, Successful informatization $=$ transformation of the educational process in the digital educational environment, Problems of modern education 2 (2016) 7-19 (In Russian).

[2] O.N. Apanasenko, E.V. Malyukova, Organizational and legal problems of quality and efficiency of distance education in Russia and abroad, in: O.N. Shirokov [et al.] (Eds.), Proceedings of the $2^{\text {th }}$ International Research-to-practice Conference on Education and science in modern environment, volume 1 of SCC "Interaktiv plus", LLC, Cheboksary, 2015, pp. 30-32. (In Russian).

[3] T.V. Nikulin, E.B. Starichenko, Informatization and digitalization of education: concepts, technologies, management, Pedagogical Education in Russia 8 (2018). http://journals.uspu.ru/attachments/article/2133/14.pdf (In Russian). doi: 10.26170/po18-08-15.

[4] P. Serdyukov, Formalism in online education", Journal of Research in Innovative Teaching \& Learning 14 (2021). https://doi.org/10.1108/JRIT-02-2021-0010.

[5] R.M. Safuanov, M.Y. Lekhmus, E.A. Kolganov, Digitalization of Education System, Bulletin of UGNTU. Science, education, economy. Series "Economics" 2 (28) (2019). (In Russian). doi: 10.17122/2541-8904-2019-2-28-108-113.

[6] N.V. Dneprovskaya, Assessment of Russian higher education readiness to digital economy, Statistics and Economics 4(15) (2018). (In Russian). doi: 10.21686/2500-3925-2018-4-16-28.

[7] A.V. Makeeva, O.I. Vaganova, J.V. Smirnova, Applying different forms of information and communication technology in a digital educational space, Innovative Economy: prospects for development and improvement 6 (2018) 126-130. (In Russian).

[8] I.D. Stolbova, E.P. Aleksandrova, K.G. Nosov, The functionality of information technology in geometer-graphic training of an engineer, Open education 1 (2017). (In Russian). doi: 10.21686/1818-4243-2017-1-59-67.

[9] S.D. Karakozov, V.D. Manyakhina, Professional-oriented components of electronic educational environment of pedagogical university, Teacher XXI century 1 (2017) 31-39. (In Russian). 
[10] I. N. Kim, Competence-based education in an innovative format, Higher education today 11 (2018) 12-18. (In Russian). doi: 10.25586/RNU.HET.18.11.P.12.

[11] I. Yu. Amirjanova, V. G. Vitkalov, Modern state of development of geometric-graphic culture and competence of future specialists, Vector of Science of Togliatti State University 2(2) (2015) 26-31. (In Russian).

[12] I. D. Stolbova, E. P. Alexandrova, L. G. Kochurova, Logic of graphic education innovations, Open and distance education 2 (2019). (In Russian). doi: 10.17223/16095944/2/4.

[13] I.D. Stolbova, E.P. Aleksandrova, M.N. Kraynova, L.V. Kochurova On creating an educationalmethodical complex to support graphic training of students, Geometry and graphics 2(3) (2015). (In Russian). doi: 10.12737/12166.

[14] I.D. Stolbova, L.V. Kochurova, K.G. Nosov, To the question of digital transformation of subject teaching, Informatics and Education 9 (318) (2020). (In Russian). doi: 10.32517/0234-04532020-35-9-53-63.

[15] L.V. Kochurova, L.A. Kuznetsova, O.V. Stolbov, I.D. Stolbova, Monitoring the quality of graphic training on the basis on the automated control system, Proceedings of the $7^{\text {th }}$ International Internet - Conference Problems of quality of students' graphic training in technical university: traditions and innovations, volume 1 of Federal state budgeted educational institution of high professional education Perm State National Research Polytechnical University, Perm, 2017, Vol. 1, pp. 304-320. (In Russian).

[16] I. Chirikov, T. Semenova, N. Maloshonok, Er. Bettinger and R. F. Kizilcec, Online education platforms scale college STEM instruction with equivalent learning outcomes at lower cost, Science Advances 15(6) (2020). doi: 10.1126/sciadv.aay5324.

[17] F.I. Sobyanin, I.V. Irkhina, V.L. Kondakov, B.J. Umarova, J. Narimanova, R.E. Kovaleva, Distance learning during the pandemic: for and against, Modern problems of science and education 2 (2021). (In Russian). doi: 10.17513/spno.30762 URL: http://scienceeducation.ru/ru/article/view?id=30762.

[18] M.A. Vinichenko, I.V. Petrova, Study of student attitude to distance learning technologies, Modern problems of science and education 1 (2021). (In Russian). doi: 10.17513/spno.30484. URL: http://science-education.ru/ru/article/view?id=30484.

[19] Statistical data, 2021. URL: https://www.easycounter.com/report/do3.pstu.ru. 